\title{
XII \\ TRAJETÓRIA DO ATENDIMENTO EDUCACIONAL ESPECIALIZADO ÀS PESSOAS COM DEFICIÊNCIA VISUAL NO OESTE DO PARANÁ: UMA HISTÓRIA QUE PRECISA SER DOCUMENTADA*
}

\author{
Luzia Alves da Siva \\ Lucia Terezinha Zanato Tureck \\ Patrícia da Silva Zanetti
}

A segunda metade do século XX marcou o período de colonização do oeste do Paraná, promovendo o crescimento populacional e econômico, destacando-se a instalação do município de Cascavel ao final do ano de 1952, o qual constituiu-se em polo regional, sendo desmembrado de Foz do Iguaçu.

Por volta das décadas de 1970 e 80, a expansão econômica impulsionou a educação pela necessidade da formação de trabalhadores, tanto na educação básica como no ensino superior, neste registrando-se a criação de Faculdades Municipais, embrionárias da Universidade Estadual do Oeste do Paraná (UNIOESTE), instituída em 1995: em Cascavel, a FECIVEL; em Foz do Iguaçu, a FACISA; em Marechal Cândido Rondon, a FACIMAR e, em Toledo, a FACITOL.

No que se refere à Educação Especial, no âmbito público, havia atendimento aos alunos com deficiência intelectual em classes especiais em algumas escolas estaduais e iniciou também na rede municipal, como relata Taborda (2006):

No município de Cascavel, a Secretaria Municipal de Educação a partir da década de 1970, verifica a urgência de estar oferecendo educação especializada a esses alunos mediante a implantação de classes especiais nas escolas da rede municipal. Nesse sentido, em 1978 os profissionais da secretaria formulam um projeto para a implantação das classes especiais, analisando e expondo as condições favoráveis bem como as dificuldades para consolidação dessas classes (TABORDA, 2006, p. 111).

*DOI - 10.29388/978-65-86678-77-2-0-f.166-178 
Quanto ao atendimento às outras áreas de deficiência, seguiram-se as tendências da época com iniciativas comunitárias na fundação de entidades filantrópico-assistenciais, de cunho educacional e terapêutico embasados nos pressupostos biológicos da deficiência, com o denominado modelo de integração, conforme expõe Taborda (2006, p. 106), referindo-se a elas: “[...] buscavam atuar significativamente na normalização do aluno, ou seja, provocar mudanças no indivíduo a fim de que este adquirisse as características necessárias para que poder estar se inserindo na sociedade".

Nesse contexto, mediante a organização de pais e familiares, foi criada a Associação de Pais e Amigos dos Excepcionais (APAE), que passa a ser a mantenedora de uma escola especial, a partir da data de 4 de maio de 1973, para que seus filhos pudessem receber uma educação que atendesse às suas necessidades educacionais, "sempre visando o desenvolvimento bio-psicosocial do excepcional, para torná-lo útil e produtivo na família e na sociedade" (TABORDA, 2006, p. 102).

A escola se manteve, e ainda se mantém mediante convênios firmados junto ao município e ao estado, por ter um caráter filantrópico-assistencial, com cedência de professores, também recebendo ajudas oferecidas pela comunidade.

Mesmo que a escola da APAE tentasse abarcar todos os atendimentos, não possuía os profissionais especializados necessários para todas as áreas. Assim, pais de alunos surdos organizaram-se na busca de uma instituição que atendesse às necessidades para melhoria do atendimento aos seus filhos: "[...] em novembro de 1975 foi criada a Associação Cascavelense de Amigos dos Surdos (ACAS). Em 1976, começou a funcionar a primeira classe especial para alunos surdos no Colégio Estadual Washington Luiz, permanecendo ali até 1978" (TABORDA, 2006, p. 106).

Com o aumento da demanda por atendimento às crianças surdas, a ACAS criou o Centro de Reabilitação Tia Amélia, em 1977, mais tarde sendo escola especial, que funcionou inicialmente em uma casa cedida pela igreja presbiteriana e que, "a partir de 1985, o Centro foi integrado pelas irmãs da Pequena Missão para Surdos, as quais, junto com a ACAS, os pais e a comunidade, e através de convênios com órgãos governamentais, doações de entidades da Itália e da Alemanha, construíram o prédio próprio" (TABORDA, 2006, p. 107).

Em relação às pessoas com deficiência visual, Taborda (2006) aponta que sua educação "insere-se no âmbito das iniciativas públicas, visto que não existe nenhum registro de instituição privada que tenha se dedicado à educação de cegos em nosso município" (p. 114). As iniciativas públicas deramse a partir de 1987. 
Foi a partir de 1983, com a abertura política, que "a educação no Estado do Paraná entrou num processo de democratização e, na educação especial, essa tendência manifestou-se pela descentralização e interiorização de serviços educacionais, com ênfase no apoio à escolarização (TURECK, 2003, p. 53). Realizou-se uma política de descentralização administrativa que se concretizou na "[...] a criação das equipes de ensino de Educação Especial nos Núcleos Regionais de Educação, as quais desempenharam relevante papel no processo de interiorização da Educação Especial" (PARANÁ, 1994, p. 11).

A prioridade da política no Estado do Paraná para os alunos com deficiência, após a década de 1980, baseou-se no apoio à escolarização pela rede pública estadual de ensino, como exposto:

Ao criar os Centros de Atendimento Especializado, nas áreas de deficiência auditiva, física e visual - CAEDA / CAEDF / CAEDV, o Departamento de Educação Especial explicitou que a educação dos indivíduos com deficiência nessas áreas é na escola comum, com a responsabilidade e competência da educação especial nos programas de apoio especializado, concomitantes ao processo escolar, em contra turno (TURECK, 2003, p. 53).

No município de Cascavel, o atendimento educacional especializado às pessoas cegas e com baixa visão teve seu início na década de 1980, quando o Departamento de Educação Especial - DEE, da Secretaria de Estado de Educação - SEED, firmou convênio com a Faculdade de Filosofia Ciências e Letras de Cascavel - FECIVEL, hoje Universidade Estadual do Oeste do Paraná UNIOESTE, com o objetivo de especializar professores ofertando Cursos de Formação para Educação Especial, na modalidade de Estudos Adicionais, em nível de ensino médio, nas áreas de deficiência mental, auditiva e visual. Dessa forma, em 1987 houve oferta de turmas nas três áreas de deficiência, o mesmo ocorrendo em 1991; reiniciando em 1993, com ofertas de turmas até 1998. Em 1991, houve turmas também na FACISA e na FACITOL. Os Cursos tinham duração de 990 a 1005 horas, com dois blocos curriculares - formação geral e específica, incluindo estágio supervisionado. Com essa formação, concretizou-se a possibilidade de abertura de Centros de Atendimento Especializado, bem como de Escolas Especiais em toda região oeste do Paraná, pois os cursos ocorriam em finais de semana, permitindo a frequência de professores que não residiam em Cascavel, Foz do Iguaçu ou Toledo.

Essa formação através dos Estudos Adicionais em nível médio exigia o Curso Normal ou Magistério, em cujo diploma era apostilado, e era aceito pelo Estado conforme disposto pelo Conselho Estadual de Educação, na Deliberação no 020/1986, no artigo 20. Após a promulgação da Lei no 9.393/1996, passa a 
ser exigida a formação dos professores em nível superior, como determina o mesmo Conselho através da Deliberação no 02/2003, no artigo 33.

Os Centros de Atendimento Especializado foram instituídos pela Deliberação 020/1986. O art. 43 apresenta que: "Os centros de atendimento especializado, criados pela SEED em estabelecimentos de ensino ou em outros espaços cedidos pela comunidade, destinam-se a alunos de diferentes escolas ou não escolares que necessitam de atendimento especializado" (PARANÁ, 1986, p. 13).

Assim, abriram-se Centros de Atendimento Especializado por todo o interior do estado, derrubando a hegemonia da capital, avançando também em relação à superação do modelo assistencialista-filantrópico, pois, a oferta desses serviços na rede pública diminuiu a criação de entidades privadas. Temse que, na década de 1980, foram criadas 09 instituições especializadas na área da deficiência visual; também 117 CAEDVs e 02 Programas de Educação Especial Supletivo (PEES) na área da deficiência visual, ofertados em escolas regulares (PARANÁ, 1994).

Em relação a Cascavel, Tureck (2003) descreve as primeiras movimentações ocorridas, inclusive em relação à sociedade:

O movimento ocorrido em Cascavel, Paraná, faz parte dessa história. Com a criação do primeiro Centro de Atendimento Especializado para Deficientes Visuais (CAEDV), em 1987, iniciou-se uma mobilização pela identificação e encaminhamento de crianças e jovens com deficiência visual às escolas. Um grupo de professoras tomou a iniciativa de convidar a comunidade a participar da educação dos cegos e fundaram a APADEVI de Cascavel, não com o objetivo de implantar programas educacionais, mas de aproximar os pais.

Com a participação de jovens e adultos cegos, o debate sobre a condução dos interesses e a luta pela concretização dos direitos dos indivíduos cegos provocou um movimento que culminou com a alteração do caráter da associação, manifesto desde a mudança do nome: Associação Cascavelense de Deficientes Visuais (ACADEVI), uma entidade de defesa de direitos e integra o Fórum Municipal de Defesa dos Direitos das Pessoas com Deficiência, criado em dezembro de 1995, em Cascavel (TURECK, 2003, p 49).

Merece menção a criação desse movimento social que têm desempenhado papel destacado na luta das pessoas com deficiência por educação, trabalho, transporte... sendo determinante para a criação do Programa de Educação Especial (PEE) da Unioeste, em 1997, o qual proporcionou e continua proporcionando apoios para o ingresso e a 
permanência das pessoas com deficiência em seus cursos, alcançando resultados significativos especialmente com pessoas cegas e com visão reduzida, acadêmicos com deficiência em maior número de concluintes na graduação e pós-graduação (PÁDUA, 2018; TURECK et alli, 2018; DALGALO et alli, 2016).

Ao término do Curso de Estudos Adicionais na área visual, em julho de 1987, o primeiro CAEDV foi criado junto ao Colégio Estadual Eleodoro Ébano Pereira, na área central de Cascavel, contando inicialmente com a atuação de cinco professoras. Um segundo CAEDV foi criado em 1989, junto ao Colégio Estadual Presidente Castelo Branco, no bairro Parque São Paulo, na direção da área sul da cidade, com uma professora atuando em um período de vinte horas, sendo posteriormente ampliado o atendimento para quarenta horas. Em 1992, um terceiro CAEDV no bairro São Francisco, na área norte, no Colégio Estadual Marcos Schuster, com a mesma capacidade de atendimento do anterior.

Em 1992, o atendimento nos CAEDVs foi orientado pelo Documento "Proposta educacional para atendimento à pessoa portadora de deficiência visual", onde consta:

$\mathrm{O}$ atendimento educacional aos cegos, em conformidade com as etapas do desenvolvimento humano, compreende: a intervenção precoce, a estimulação essencial e o período preparatório para a alfabetização, a faixa escolar, o adolescente e o adulto. Dentre as atividades previstas, salientam-se o desenvolvimento tátil, o braile, sorobã, atividades de vida diária, orientação e mobilidade, apoio escolar, preparação para o trabalho e socialização. Para os alunos com visão reduzida, o atendimento é dirigido para o desenvolvimento do funcionamento visual, através de exercícios específicos adaptados a cada caso, com orientações de oftalmologistas (TURECK, 2003, p. 55-56).

Ainda no ano de 1992, a Superintendência da Educação (SUED) e o DEE publicam a Instrução Normativa n.o 02/92, que estabeleceu critérios para a condução da Educação Especial no processo de municipalização do ensino. Assim, essa Normativa incumbiu os municípios da responsabilidade pelos CAEDVs, que recentemente haviam sido criados, mantendo-se assim uma parceria entre o Estado e os municípios. No ano de 1994, o DEE apresentou o documento "Fundamentos teórico - metodológicos para a Educação Especial", o qual orientava o atendimento aos alunos com deficiência na rede regular de ensino do Estado do Paraná. Sobre o atendimento realizado pelos CAEDVs assim constava: 
Os Centros de Atendimento Especializado (CAEDV) constituir-se-ão unicamente em suporte pedagógico ao aluno portador de deficiência visual e ao professor do ensino regular. A matrícula desses educandos nos CAEDV é opcional e deverá ocorrer, sempre, em período contrário ao da escolaridade regular, sendo que a freqüência é obrigatória (PARANÁ, 1994, p. 69).

Em relação ao atendimento de alunos com deficiência visual, o documento era explícito na concepção biológica da deficiência, com ênfase no defeito visual, sendo supervalorizadas as informações do laudo médico, em detrimento de informações pedagógicas, como se lê:

O laudo oftalmológico se caracteriza como instrumento formal de avaliação, considerado de fundamental importância no processo de avaliação, pois, a partir dele, o professor deduzirá o grau de comprometimento visual, que poderá variar da cegueira, visão reduzida (subnormal), até problemas de ambliopia ou de alta refração (PARANÁ, 1994, p. 37 - grifo do autor).

Em relação à avaliação do desempenho visual, é colocado que: "de posse do laudo oftalmológico, os professores levantam dados, através de instrumentos informais e formais de avaliação sobre o nível do desenvolvimento viso-perceptivo e suas implicações na área educacional" (PARANÁ, 1994, p. 37). As informações obtidas nessa avaliação "nortearão o planejamento do professor na busca da melhoria do desempenho da eficiência visual de seus alunos, que incidirá, consequentemente, no progresso da aprendizagem" (PARANÁ, 1994, p. 38).

Em 2010, foi publicada a Instrução n.o 020, estabelecendo orientações para organização e funcionamento do Atendimento Educacional Especializado (AEE) na Área da Deficiência Visual, sendo a primeira Instrução a estabelecer diretrizes para o atendimento de alunos cegos e com baixa visão, seguindo as Diretrizes Nacionais para a Educação Especial na Educação Básica (BRASIL, 2001), ao tratar o atendimento como parte do AEE e as demais normas definidas a partir da Política Nacional de Educação Especial na Perspectiva da Educação Inclusiva (BRASIL, 2008).

Reza a Instrução n.o 020/2010 que o AEE na área da deficiência visual deve ocorrer nas Salas de Recursos Multifuncionais Tipo II e nos CAEDVs; sendo a oferta no turno inverso ao da escolarização, não substituindo as classes comuns, podendo funcionar nas redes estadual, municipal e particular, bem como, em instituições comunitárias ou filantrópicas sem fins lucrativos, 
conveniadas com a Secretaria de Educação ou órgão equivalente (PARANÁ, 2010).

A Instrução apresenta as Salas de Recursos Multifuncionais Tipo II, que advém da política do governo federal, criadas a partir da Portaria Normativa n. -13 , de 24 de abril de 2007. Estas Salas de Recursos, que são denominadas do Tipo II quando direcionadas aos alunos com deficiência visual, proporcionaram a disponibilização de equipamentos que compõem um kit que a escola recebe quando da sua implementação: máquina de datilografia Braille, impressora Braille, notebooks, lupas, sorobãs...

Em 2016, a SEED publicou a Instrução n. 06/2016, a qual estabelece critérios para o AEE em Sala de Recursos Multifuncionais no Ensino Fundamental - anos finais e Ensino Médio - Deficiência Visual. A partir dessa Instrução, o Estado do Paraná deixa de aplicar o termo CAEDV ao programa que realiza $o$ atendimento no contraturno na rede regular de ensino, que passa a ser denominado de Sala de Recursos Multifuncional - área visual. Não há mudanças profundas na Instrução, além de deixar de considerar a Educação Infantil e o Ensino Fundamental anos iniciais; embora entenda que o atendimento deve ser iniciado a partir dos 06 anos para os alunos regularmente matriculados; entende as crianças menores como pessoas da comunidade com cegueira ou baixa visão, desconsiderando a legislação que torna obrigatória a escolaridade a partir dos 4 anos. Ainda, excluía a possibilidade de atendimento às pessoas adultas não matriculadas na rede estadual, o que causou reações no movimento social de pessoas cegas, pois considera-se pertinente os adultos poderem ser ali atendidos, já que não há outro espaço para tal atendimento, e é considerável a ocorrência de pessoas da comunidade em geral que perdem a visão. Embora sempre na berlinda para sua extinção, o atendimento às pessoas cegas e com baixa visão da comunidade tem sido defendido pelo movimento de pessoas com deficiência visual como um atendimento necessário e fundamental ofertado na rede regular de ensino. Sem ele essas pessoas estariam abandonadas à sua própria sorte, sem um atendimento que pudesse lhe possibilitar o conhecimento dos diversos recursos para enfrentarem a situação da perda da visão e a retomada, quando necessária, de seus estudos e de sua vida laboral e em sociedade.

O fato de alunos cegos ou com baixa visão estudarem na rede regular de ensino não significa que todas as suas especificidades e necessidades estejam automaticamente supridas. Para que eles possam frequentar a escola comum, tendo acesso aos conhecimentos historicamente produzidos pela humanidade, conhecimentos científicos que compõem o currículo escolar, são necessários recursos e equipamentos adaptados, a exemplo de máquina de datilografia braille, reglete, punção, sorobã, lupas, livros didáticos em braille e 
com caracteres ampliados, entre outros, além do conhecimento e uso da informática acessível. Dessa forma:

Com o objetivo de suprir, ao menos em parte, esta demanda, em 1995, com a aquisição de algumas impressoras braile, computadores e outros recursos necessários, o governo do Estado, através do DEE, atendendo diversas reivindicações do movimento das pessoas cegas ou com visão reduzida de todo o Estado, deu início à implantação das Centrais de Produção de Material em Braile. [...] os equipamentos adquiridos pelo DEE foram repassados para alguns municípios mediante termo de concessão de uso, por meio dos quais os municípios assumiam não só a responsabilidade com a guarda e a sua conservação, como também precisavam fazer a manutenção dos equipamentos, assumir o espaço físico, funcionários e demais materiais de expedientes (ROSA, 2008, p. 23).

$\mathrm{O}$ atendimento na área de produção de material em Braille na cidade de Cascavel deu-se no mês de novembro de 1997, com a implantação de uma Central de Produção de Material em Braile. Foi efetuada parceria entre a SEED e a Prefeitura Municipal de Cascavel, que firmou convênio com a ACADEVI durante quatro anos para a contração de pessoal. Essa parceria visava à disponibilidade de profissionais com deficiência visual para trabalhar na produção e revisão dos livros impressos em braille.

O objetivo das Centrais de Produção de Material em Braile não ultrapassava o que o seu nome já diz, a produção de livros didáticos em braille. Felizmente, a preocupação com a produção dos livros adaptados aos alunos cegos e com baixa visão, bem como um atendimento mais amplo às especificidades da área visual ocorria em outros estados brasileiros, culminando com o estabelecimento por parte do MEC de uma política para este fim. Nesse bojo, foram criados os Centros de Apoio Pedagógico para Atendimento às Pessoas com Deficiência Visual (CAP) no final da década de 1990.

A implementação dos CAPs foi realizada pelo MEC, através da Secretaria de Educação Especial (SEESP), sendo resultado de um trabalho conjunto daquela Secretaria e das entidades filiadas à União Brasileira de Cegos (UBC): Associação Brasileira de Educadores de Deficientes Visuais (ABEDEV), Instituto Benjamin Constant (IBC) e Fundação Dorina Nowill para Cegos. O projeto foi inspirado em uma experiência exitosa da Secretaria de Educação do Estado de São Paulo. O objetivo do MEC era a implantação de, pelo menos, uma unidade em cada estado brasileiro, no período de 1998 a 2001. 
No Paraná, os CAPs foram instituídos pela Resolução n.o 2473-GS/SEEB/2001, "com a finalidade de garantir a inclusão da pessoa com deficiência visual no sistema regular de ensino, bem como promover o pleno desenvolvimento e a integração desses alunos em seu grupo social" (PARANÁ, 2001). Tal finalidade se apresenta através da oferta de serviços de apoio pedagógico complementar, que se concretizam por meio de 04 núcleos de atuação: I - de Apoio Pedagógico; II - de Produção Braille; III - de Tecnologia; e IV - de Convivência. A Resolução garantiu que, apesar de o CAP possuir sede em Curitiba, poderia atuar de forma descentralizada, por meio da criação de Centros em outros municípios do Estado. Assim, as Centrais de Produção de Material em Braille foram transformadas em CAPs, sendo sediadas nas cidades de Cascavel, Francisco Beltrão, Maringá e Londrina.

Em Cascavel, a Central de Produção Braille teve sua autorização de funcionamento concedida em 2002, como uma descentralização do CAP Paraná. Naquela época, a área de abrangência do CAP se referia aos NRE de Cascavel, Foz do Iguaçu, Assis Chateaubriand e Toledo e, em consequência, aos seus municípios jurisdicionados. Atualmente o CAP atende a mais um NRE, o de Goioerê, totalizando 59 municípios.

Em 2004, o CAP já enfrentava dificuldades com a impressão dos livros em braille para os alunos cegos; a compra das impressoras só ocorreu após a ACADEVI realizar uma manifestação que levou cerca de 80 pessoas cegas e com baixa visão a protestar em frente do NRE de Cascavel.

Os 04 núcleos do CAP enfrentaram dificuldades para serem implantados. Com o concurso público para professores da Educação Especial, ocorrido em 2004, no qual os professores assumiram em 2005, foram conseguidas as 400 horas previstas para seu funcionamento. Com isso, o CAP começou a desenvolver mais cursos de formação para professores e pessoas com deficiência visual e gradativamente ampliou esta demanda.

A partir da Instrução no 013/2011, da SEED, além das pessoas com deficiência visual, o CAP deve atender às necessidades dos alunos com surdocegueira. A Instrução também permite que em seu Núcleo de Convivência se realizem ações com entidades de pessoas com deficiência; assim, o CAP tem realizado inúmeras atividades em parceria com a ACADEVI.

Segundo a referida Instrução, é uma das finalidades do CAP:

2.1. Contribuir na oferta de suportes teóricos e práticos aos profissionais que atuam no processo educacional das pessoas com deficiência visual e surdocegueira, visando seu processo acadêmico na educação inclusiva por meio de formação continuada de professores, profissionais e outros que atuam com as pessoas com essas deficiências e ainda os que 
atendem a esses alunos no processo de inclusão, visando a melhoria e ampliação dos serviços e programas de atendimentos especializados bem como na Educação Básica, produção de materiais, atividades de convivência, acesso às novas tecnologias, trabalho com Atividade de Vida Autônoma - AVA e Orientação e Mobilidade - OM e atendimento às pessoas com deficiência que estão fora do processo acadêmico (educação básica) no que se refere a reabilitação e estimulação essencial (PARANÁ, 2011, p. 01).

Cumprindo suas funções, conforme apontam relatórios, foram realizadas pelo CAP atividades de formação continuada de professores e atividades direcionadas às próprias pessoas com deficiência visual, sintetizando de 2005 a 2019: 70 atividades, 1.034 participantes e 3.894 horas de atividades, como: Cursos de Braille; de Sorobã e do uso do Multiplano; Orientação e Mobilidade; Atividades de Vida Diária; Tecnologias, envolvendo o uso do sistema DOSVOX, do Jaws e NVDA; Atendimento aos alunos com Baixa Visão; Educação do aluno com Deficiência Visual na Escola Comum e o Papel da Equipe Pedagógica; Grupo de Estudos sobre Surdocegueira, sobre os Pressupostos metodológicos e as diferentes perspectivas de existência para as pessoas com deficiência visual na atual formação societária, sobre Reflexões sobre as Normas Técnicas para a Produção de livros para alunos com Deficiência Visual; Ciclo de Estudos - A educação das pessoas com deficiência visual: o processo aprendizagem e desenvolvimento na perspectiva históricocultural.

Tais atividades não poderiam ser realizadas sem a colaboração do PEE da Unioeste, que além de garantir a certificação também tem apoiado na realização destes cursos. O CAP municipal de Cascavel também tem sido parceiro na realização das atividades. Vale destacar que este centro, assim como o CAP Estadual também possui a incumbência de prestar o suporte administrativo e didático-pedagógico necessário à implementação de ações relativas à escolarização de pessoas cegas e com visão reduzida em âmbito da rede escolar do município de Cascavel.

Constitui-se relevante enfatizar que, é na parceria com a Unioeste, pelo $\mathrm{PEE}$, do qual a ACADEVI também participa, que a fundamentação teórica da Psicologia Histórico Cultural e da Pedagogia Histórico Crítica tem se materializado nos estudos da equipe do CAP e subsidiado a formação dos professores ofertada. Com estes fundamentos, supera-se a visão biológica da deficiência, que é fatalista e imputa a cegueira ao indivíduo, como uma tragédia e um problema que é dele e de sua família, desconsiderando sua totalidade. Pela visão científica, Vigotski (1997) defende que: 
[...] as leis que dirigem o desenvolvimento, tanto da criança normal como a que possui uma deficiência, na base são as mesmas, igualmente às leis da atividade vital, fundamentalmente são iguais em condições normais como em condições de enfermidade do funcionamento de algum órgão ou do organismo em geral (VIGOTSKI, 1997, p. 173).

E mais ainda, que o ensino de alunos com deficiência necessita seguir os mesmos princípios teórico-metodológicos que norteiam o ensino dos demais alunos. Nessa perspectiva, conforme aborda Silva et alli (2017), tais aspectos pressupõem a compreensão por parte dos professores de que alunos com deficiência visual possuem as potencialidades e as habilidades necessárias aos processos de aprendizagem e de desenvolvimento e que estas estarão dadas com maior ou menor intensidade em acordo com as experiências sociais vivenciadas e com as atividades intencionais e mediadas a eles disponibilizadas durante sua escolarização. Nessa direção, o desafio colocado atualmente diz respeito à luta pela alteração da ênfase dos princípios norteadores do ensino de alunos com deficiência visual: de uma concepção biológica, focada no defeito visual para uma concepção histórica e social, que conceba o sujeito com deficiência visual na sua totalidade, com potencialidades e habilidades dadas a partir dos níveis de aprendizagem e de desenvolvimento em que se encontra.

Para finalizar, destacam-se os avanços alcançados até aqui e enfatizase que estes não teriam sido possíveis se não houvesse a luta e o empenho do movimento organizado das pessoas com deficiência visual de Cascavel e região, o qual possibilitou e ainda hoje busca possibilitar significativas contribuições à implementação de políticas educacionais destinadas às pessoas com deficiência visual. Essas contribuições se materializam não só na participação coletiva no planejamento das ações, mas, principalmente, na sugestão de estratégias e de encaminhamentos adequados às reais necessidades dessa parcela da população.

\section{REFERÊNCIAS}

BRASIL. Ministério da Educação. Conselho Nacional de Educação. Resolução no 02/2001. Diretrizes Nacionais para a Educação Especial na Educação Básica. Brasília, 2001.

BRASIL. Ministério da Educação. Secretaria de Educação Especial. Política Nacional de Educação Especial na Perspectiva da Educação Inclusiva. Brasília, 2008. 
CASCAVEL. Lei n. 4126, de 07 de novembro de 2005. Cria o Centro de Apojo Pedagógico às Pessoas cegas ou com Visão Reduzida (CAP). Cascavel, 2005.

DALGALO, Vanderlize S.; IACONO, Jane P.; SILVA, Dorisvaldo R. da; SILVA, Vera L. R. R. da; TURECK, Lucia T. Z. O atendimento educacional especializado (AEE) na Unioeste frente às novas demandas. ANAIS DO 70 CONGRESSO BRASILEIRO DE EDUCAÇÃO ESPECIAL, 2016, São Carlos, São Paulo. Anais eletrônicos... Campinas, SP, Galoá, 2020. Disponível em:

https://proceedings.science/cbee/cbee7/papers/o-atendimento-educacionalespecializado--aee--na-unioeste-frente-as-novas-demandas. Acesso em: 2 mai. 2020.

PÁDUA, Ivã José de. 0 papel dos movimentos sociais das pessoas com deficiência na efetivação de políticas educacionais de acesso ao ensino superior na UNIOESTE. 2018. 159 f. Dissertação (Mestrado). Programa de Pósgraduação em Educação. Universidade Estadual do Oeste do Paraná, Cascavel, PR, 2018.

PARANÁ. Conselho Estadual de Educação. Deliberação n.o 020/86. Indica Normas para a Educação Especial no Sistema de Ensino. Curitiba, 21 de novembro de 1986.

PARANÁ. SEED. SUED. DEE. Instrução n. 02/92. Dispõe sobre o Critério para a condução de Educação Especial no processo de Municipalização do Ensino. Curitiba, 1992.

PARANÁ. Secretaria de Estado da Educação. Departamento de Educação Especial. Fundamentos teórico - metodológicos para a Educação Especial. Curitiba, 1994.

PARANÁ. Secretaria de Estado da Educação. Resolução n.o 2473-GS/SEEB. Dispõe sobre a criação do CAP-PR Centro de Apoio Pedagógico para Atendimento às Pessoas com Deficiência Visual, do Estado do Paraná. Curitiba, 2001.

PARANÁ. Secretaria de Estado da Educação. Superintendência da Educação. Instrução n.o 013/2011. Dispõe sobre as orientações para organização e funcionamento dos Centros de Apoio Pedagógico para Atendimento às Pessoas com Deficiência Visual. Curitiba, 2011.

PARANÁ. Secretaria de Estado da Educação. Superintendência da Educação. Instrução n.o 020/2010. Dispõe sobre as orientações para organização e funcionamento do Atendimento Educacional Especializado na Área da Deficiência Visual. Curitiba, 2010. 
PARANÁ. Secretaria de Estado da Educação. Superintendência da Educação. Instrução n.o 06/2016. Estabelece critérios para o Atendimento Educacional Especializado em Sala de Recursos Multifuncionais no Ensino Fundamental anos finais e Ensino Médio - Deficiência Visual. Curitiba, 2016.

ROSA, Enio Rodrigues da. A educação escolar das pessoas cegas ou com visão reduzida no Estado do Paraná. In: FIUZA, A. F; CONCEIÇÃO, G. H. da. Política, Educação e Cultura. Cascavel, PR: EDUNIOESTE, 2008. p. 11-32.

SILVA, Luzia Alves da; TURECK, Lucia Terezinha Zanato; ZANETTI, Patrícia da Silva. Vigotski e os Fundamentos da Defectologia. ANAIS DA XIV JORNADA DO HISTEDBR: Pedagogia Histórico-Crítica, Educação e Revolução: 100 anos da Revolução Russa. Anais... UNIOESTE - Foz do Iguaçu, PR - 3 a 5 de maio de 2017.

\section{TABORDA, Benhur Wagner. Aspectos Históricos da Educação Especial no}

Município de Cascavel: dos primórdios à regionalização dos serviços especializados. Monografia (Especialização) História da Educação Brasileira/HISTEDOPR. Universidade Estadual do Oeste do Paraná - UNIOESTE, Cascavel, PR, 2006.

TURECK, Lucia Terezinha Zanato. Deficiência, educação e possibilidades de sucesso escolar: um estudo de alunos com deficiência visual. 2003. $118 \mathrm{f}$. Dissertação (Mestrado). Pós-graduação em Educação. Universidade Estadual de Maringá. Maringá, PR, 2003.

TURECK, Lucia Terezinha Zanato; IACONO, Jane Peruzo; DALGALO, Vanderlize Simone; OLIVEIRA, Edinei de. A interação da Unioeste com entidades de pessoas com deficiência como fator de acessibilidade ao ensino superior. XVIII Seminário de Extensão da Unioeste. Anais... Foz do Iguaçu, Paraná, 19 a 21 de junho de 2018. p. $70-75$.

VIGOTSKI, L. S. Obras completas. Fundamentos da defectologia. Tomo V. Havana: Editorial Pueblo y Educación, 1997. 